\title{
Platform Economy and Internet Platform Monopoly
}

\author{
Jiuding Li, Shuaiming Gao \\ Yantai Research Institute, China Agricultural University, Yantai, Shandong 264670, China
}

\begin{abstract}
With the development of computer technology and network technology, the era of digital economy has arrived, the Internet platform economy has flourished, and a number of Internet enterprises with certain influence have emerged at home and abroad. Among them, the large Internet enterprises use their own platform's advantageous position in data, traffic and algorithms to interdepend on and influence each other, thus leading to the price of commodities not only determined by market supply and demand but more influenced by the oligarchs through some tangible or intangible ways of price leadership. Internet platform vendors take a cut from both the supply and demand side, capturing excess profits in the hands of the platform to the detriment of the majority. Internet platforms are not a place outside the law and the platform economy should operate under good market rules and market competition, while the state should also amend its antimonopoly laws in due course to meet the needs of the market at this stage.
\end{abstract}

Keywords: Platform Economy; Internet Platform; Monopoly.

\section{Analysis of the Current Situation of the Platform Economy}

Platform economy is a new economic system based on digital technology, constituted by datadriven, platform-supported and network-coordinated economic activity units, and is a general term for various economic relationships based on digital platforms.[1] In China, the platform economy, as a new driving force for economic development, touches many fields such as industry, manufacturing, retail, news and media, transportation, finance and information retrieval in China, and has an important role in promoting economic growth, enhancing innovation capacity, improving service levels, promoting industrial upgrading and stabilizing employment in various aspects, and it is estimated that the platform economy accounts for about ten percent of China's total GDP.[1] With the progress of technology, policy support and market competition, China has seen the emergence of many Internet platform economy giants such as Alibaba, Tencent, Jindo, Jingdong, Drip, Meituan and Baidu, which are related to all aspects of the country's livelihood.

\section{The Profit Model of the Platform Economy and the Creation of its Monopoly Position}

The platform economy is a business model that uses the Internet to provide a space or platform for buyers and sellers to trade and exchange activities. Unlike traditional business models, Internet platforms generally do not directly provide merchants or consumers with certain goods or services, but only serve as a trading venue and channel to facilitate the completion of transactions between buyers and sellers. It is a business model like that of a "food market". Its profitability is mainly based on commissions received from shops or sellers, plus a percentage of consumer spending. As the platform grows in size and the number of merchants and users increases, the platform can also generate revenue from merchant entry fees, advertising and promotion fees, user membership fees and service fees.

The profit model of the platform economy shows that the monopoly position of the platform economy has its roots.

Firstly, due to the special business model of the platform economy and the special and exclusive nature of the profit model, the platform economy has certain public goods properties, which also leads to the possibility of monopoly in the platform economy. Secondly, considering the platform itself, as a special "place" and "organisation", the platform economy promotes trading behaviour, and the platform will always seek to gain more markets, make more profits, complete monopolies, achieve 
price leadership and gain a special position in the market. Special status in the market. Thirdly, from the point of view of consumers and merchants, sellers always want to make their goods available to all consumers on one platform, while consumers want to buy the goods they want at only one terminal for convenience. Therefore, when the Internet platform is large enough and the platform is exclusive enough, there is a certain inevitability of the monopoly of the Internet platform.

\section{Monopoly Operation of the Platform Economy}

In the early stage of the development of platform manufacturers, platforms first attracted users through their advantages in algorithms, data and traffic, and then discounted the merchants and consumers within the platform by raising huge amounts of capital, thus attracting more merchants to the platform and more consumers to spend money on the platform, so that buyers and sellers gradually became dependent on the platform, thus combating competitors and enabling platform companies to reach a monopoly in the industry.

In the early years of their operations, both companies quickly divided the domestic online taxi market, each accounting for half of the domestic online taxi market, by virtue of their data, traffic and algorithm advantages, as well as the convenience and intelligent services provided to passengers. With the injection of capital from mainly Tencent and Ali, Drip Taxi and Fast Taxi began a "subsidy war", each subsidizing drivers and consumers with generous prices. Among them, DDT and WeChat Pay jointly launched a campaign, when passengers use DDT to call a taxi through WeChat Pay can immediately reduce 10-yuan taxi fare, the driver can immediately get 10-yuan reward; while fast taxi and Alipay announced that they will upgrade the subsidy scheme, fast side at the same time said that its taxi reward amount will always be one yuan higher than the peer. With competition heating up and the unsustainability of gaining market access through subsidies, the two companies opted to merge in 2015 and for DDT, completing its monopoly in the domestic online taxi market by way of restructuring and integration.

\section{Economic Analysis of the Monopolistic Phenomenon in the Platform Economy}

Suppose there is a market in which there is a platform vendor. Because a platform vendor has no similar substitutes in the market, or because competition, etc., excludes competing vendors from the market. The platform has a monopoly of Internet resources and a patent monopoly, and has a natural advantage in algorithms, data and traffic, making it largely inaccessible to other vendors, and the platform forms a monopoly in the market, thus making the market in which it operates a perfect monopoly.

In the short-term decision of a perfect monopoly market, the profit-maximising output of the vendor is $\mathrm{MR}=\mathrm{MC}$, i.e., the profit-maximising output when marginal cost is equal to marginal utility, and the number of users of the platform is huge because both consumers and merchants in the market consume and sell on the platform. pricing $\mathrm{P}>\mathrm{AC}$, the platform can earn considerable excess profits, as shown in Figure 1.

In the long-run decision in a perfect monopoly market, the platform maker can adjust all the factors of production in the long run to carry out industrial adjustment and correct the amount of inputs of the factors of production so as to maximise profits. Moreover, in a perfect monopoly market, the profit maximisation of the short-run decision of the firm is continuously maintained, which means that the profit maximisation of the long-run decision of the firm can be achieved. Therefore, the average cost in its long-term decision is equal to the short-term decision, i.e., LAC=SAC, and its profit-maximizing output in the long-term decision is $\mathrm{MR}=\mathrm{SMC}=\mathrm{LMC}$. thus, as long as $\mathrm{P}>\mathrm{LAC}=$ $\mathrm{SAC}$, the platform manufacturer can still obtain monopoly profits in the market, as shown in Figure 2. 
The above argument explains why platform vendors are scrambling to seek a monopoly position in the market.

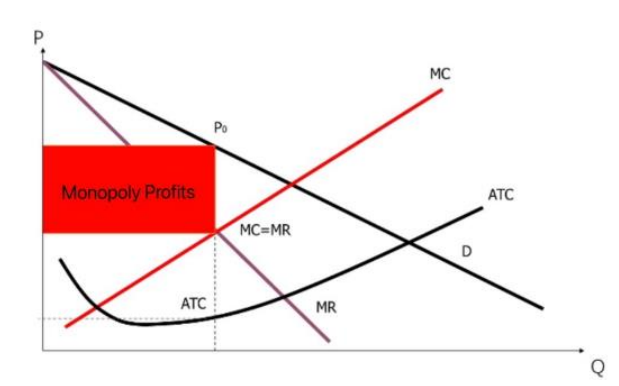

Fig 1. Monopoly profits

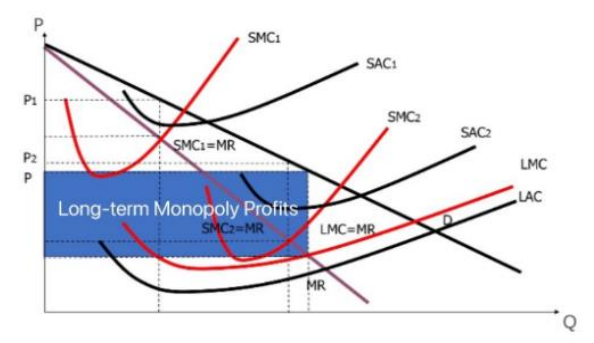

Fig 2. Long-term Monopoly profits

\section{Evaluation on Monopolistic Behavior in Platform Economy}

The monopolistic behavior of some Internet enterprises in the platform economy cannot be evaluated in a single good or bad way, but should be analyzed in a specific way by conditions, industries and situations.

On the one hand, monopoly as an economic manifestation of the market economy, if the platform is developed under a model that conforms to the market rules and forms a monopoly position, then the platform monopoly itself is not illegal, it is a reasonable manifestation of the successful operation of the enterprise and the occupation of the market. It cannot be because the platform occupies the market to take administrative measures to compel intervention and control, which is first not in line with the rules of operation of the market economy, but also not conducive to the long-term development of the industry, the negative impact of the business environment, the damage is the vitality of economic development. Secondly, as a tool and channel to connect businesses and consumers, the Internet platform has certain attributes of economies of scale, and economies of scale are an important reason for the formation of a complete monopoly market, which has the potential to promote economic efficiency.[2] Finally, Internet platform monopolies are likely to be conducive to technological innovation. After all, the power of capital is limited, but it is more about technology and innovation. Not only that, the monopoly platform can invest more capital, technology and power into scientific and technological innovation to continuously improve its core competitiveness, and its monopoly platform also provides a large amount of information and market for its innovation, so as to achieve a higher level of innovation development.

On the other hand, traditional economic theory suggests that a perfect monopoly market will reduce productivity and lower the level of welfare of the whole society. Since the platform monopolizes the market, the supply of the platform is the supply of the whole market, so when $\mathrm{MR}=\mathrm{MC}$ is the maximum profit of the platform only and not the maximum profit of the whole society, the production efficiency and welfare level of the society will be reduced due to the monopolistic market. Secondly, the platform monopoly tends to cause high prices, draws too much from buyers and sellers, and because of its special status, the platform will always practice price discrimination against different groups, thus further expanding profits and increasing revenue, resulting in the loss 
of interests of consumers and merchants. The "big data killing" is the central manifestation of this. Once again, a complete monopoly reduces market competition, and platform vendors are not under competitive pressure, thus the development of enterprises may only be a management adjustment or sequential adjustment, reducing structural upgrading and innovation. Finally, the Internet platform has a large amount of personal privacy and habitual preferences due to its own part of the public goods, so if the Internet platform is not controlled, the problem of information security will hinder social progress and damage the citizens' sense of well-being, access and security.

\section{Responses to Monopolies on Internet Platforms}

At this stage, the monopoly phenomenon of Internet platforms is still at a controllable stage. In the author's view, under the premise that the Internet platform has not affected the rules and operation of the market, the development of the platform economy is still mainly solved by market means, supplemented by government regulation and macro-control. Among them, the innovation ability and service level of enterprises should be guided at the right time to avoid the phenomenon of "big shop bullying customers". In important areas of national importance, such as finance, health care, mining and infrastructure, regulation should be strengthened and powers should be carefully delegated. At the same time, it is necessary to keep abreast of the times and formulate an anti-monopoly law that is in line with our national conditions and responds to the ever-changing domestic and international situation, thus contributing to the resolution of major risks, enhancing the well-being of the people and promoting the sound development of the socialist market economy.

The platform economy is a product of the times, [3] and data concentration is a sufficient and necessary condition for the development of the platform economy.[4] The development of Internet platforms has its own unique attributes and modes, and in promoting the development of the platform economy, the main role of the market in the allocation of resources should be given full play, supplemented by the necessary administrative and judicial means to continuously clarify the market rules and their operation laws, so as to promote economic development and people's living standards This will promote economic development and the improvement of people's living standards.

\section{References}

[1] Zhao Changwen. Pay great importance to the healthy development of platform economy [N]. Learning Times, 2019-08-14 (001).

[2] Li Chengyou, Wang Bing. On the reasons and Comments on the complete monopoly market [J]. Contemporary economic Studies.1999(10).

[3] Wang Yong, Feng Hua. Dual regulation of platform economy: Private supervision and public regulation [J]. Economist, 2017 (11): 73-80.

[4] Yang Dong, Zang Junheng. Anti-monopoly regulation of digital platforms [J]. Journal of Wuhan University (Philosophy and Social Sciences Edition), 2021,74 (02): 160-171.

[5] Wu Zhuoqun. Characteristics, status quo, and experience analysis of platform economy [J]. Competitive Intelligence, 2014 (02): 42-52.

[6] Liu Yun. International trends in Internet platform antitrust and China's response [J]. Forum on Politics and Law, 2020,38 (06): 92-101. 